\title{
Consumo de proteínas e ganho de massa muscular
}

\author{
Antônio Felipe Corrêa Marangon ${ }^{1}$ \\ Renata Adjuto de Melo ${ }^{2}$
}

\begin{abstract}
RESUMO - A prática de exercícios físicos aumenta com a busca de desenvolvimento da força e do volume muscular. Podem-se citar os exercícios de força, que promovem um turnover protéico no músculo esquelético. Portanto, aliada a esse tipo de atividade física, está a alimentação, que deve ser balanceada e baseada em determinada quantidade de proteínas para o bom funcionamento dos processos anabólicos e diminuição do catabolismo. Entretanto, a quantidade adequada, $0,8 \mathrm{~g}$ / $\mathrm{kg}$ de peso corporal para indivíduos sedentários, recomendada pela RDA, a atletas e esportistas, é questionada e ainda está sendo pesquisada com valores preliminares que variam de 1,0 a $2,0 \mathrm{~g} / \mathrm{kg}$ de peso corpóreo. Pelas necessidades do organismo, em função do desgaste muscular nos exercícios, a proteína dietética, muitas vezes, é ingerida por meio de suplementos à base de aminoácidos, que podem trazer riscos à saúde se ingerido em quantidades inadequadas, o que prejudica, também, o desempenho dos praticantes de atividade física.
\end{abstract}

Palavras-chave: proteína, anabolismo, recomendação, exercício físico, suplementos.

\section{Protein ingest and muscular mass gain}

\begin{abstract}
The practical one of physical exercises comes increasing with the search for exercises that increase the force and the muscular volume. The force exercises can be cited, that, as well as all the exercises, promote a proteic turnover in the esqueletic muscle. Therefore, allied to this type of physical activity, it is the feeding, that must be balanced and be based on one determined amount of proteins for the good functioning of the anabolic processes and reduction of the catabolism. However, this adequate amount $(0,8 \mathrm{~g} / \mathrm{kg}$ of corporal weight for sedentary individuals, recommended for the RDA) for athletes and sportists, sufficiently are questioned and still it's being searched, with preliminary values that vary of $1,0-2,0 \mathrm{~g} / \mathrm{kg}$ of corporeal weight. By the great necessities of the organism, in function of the muscular consuming in the exercises, the dietary protein, many
\end{abstract}

\footnotetext{
${ }^{1}$ Prof. de Fisiologia e Avaliação Nutricional do UniCEUB. E-mail: antonio.felipe@ uniceub.br

${ }^{2}$ Graduanda em Nutrição - UniCEUB. E-mail: teids@terra.com.br
} 
times, the amino acid base is ingested by means of supplements, which can bring risks to the health if it's ingested in inadequate amounts, also harming the performance of these practitioners of physical activity.

Key words: protein, anabolism, recomendation, physical exercise, adds.

A prática de atividades físicas regulares torna-se hábito entre os indivíduos por questão de estética corporal, busca de melhor condicionamento físico ou para a manutenção de vida saudável. (ARAÚJO et al, 1999; ROCHA et al, 1998; MARANGON, 2003) Para melhores resultados nessas atividades, os esportistas e atletas buscam o uso de suplementos alimentares em decorrência da crescente divulgação pela mídia dos efeitos benéficos à saúde. Utilizam-se esses suplementos para substituição de proteínas da dieta, aumento do valor biológico das proteínas da refeição ou, principalmente, por seus efeitos anticatabolizantes e anabolizantes. (ARAÚJO et al, 1999; ROCHA et al, 1998; MARANGON, 2003)

Os mais utilizados são as proteínas, que respondem pelo suprimento adequado de aminoácidos essenciais para garantir crescimento, desenvolvimento e reconstituição tecidual como a musculatura esquelética. Entretanto, o excesso de proteínas no organismo pode ser prejudicial, uma vez que as energias extras, em forma de proteínas, transformam-se em gorduras e são armazenadas em depósitos subcutâneos. Além disso, o excesso sobrecarrega o fígado e os rins, órgãos relacionados ao metabolismo protéico. (ARAÚJO et al, 1999; ROCHA et al, 1998)

\section{Metabolismo das proteínas}

As proteínas são formadas por subunidades denominadas aminoácidos. Oito deles podem ser sintetizados pelo corpo e, portanto, terão de ser fornecidos pelos alimentos da dieta. São os denominados aminoácidos essenciais (isoleucina, leucina, lisina, metionina, fenilalanina, treonina, triptofano, e valina). Outra classificação desses aminoácidos é dada como não-essenciais, ou seja, são fontes de proteínas corporais, encontradas no plasma, tecido visceral e músculo. Toda essa proteína faz parte das estruturas teciduais ou existe na forma de importantes componentes dos sistemas metabólicos, hormonal. (DUTRA, 1998; MCARDLE et al, 1998)

No organismo, a proteína é continuamente sintetizada e degradada (turnover), respectivamente, por meio de processos anabólicos e catabólicos. O turnover de proteínas é regulado por fatores dietéticos, hormonais (insulina, glucagon, IGF-1, entre outros) e metabólicos. (COOMES, 1998; HIRSCHBRUCH et al, 2002) 


\section{Síntese e degradação protéica}

Os aminoácidos não-essenciais são classificados em dois grupos no que diz respeito a sua síntese: os sintetizados por transferência de um nitrogênio para um esqueleto de carbono precursor originário do ciclo de Krebs ou da glicólise, e os sintetizados especificamente a partir de outros aminoácidos. Em razão de esse último grupo depender da disponibilidade de outros aminoácidos específicos, são particularmente vulneráveis para tornar-se essenciais se o suprimento de um aminoácido precursor na dieta torna-se limitado. (SHILLS et al, 2003) A função metabólica mais importante dos aminoácidos é a formação de proteínas específicas, incluindo as estruturais, como o tecido muscular, e as funcionais, como as enzimas. (COOMES, 1998)

As células corporais obtêm aminoácidos do sangue, o mecanismo genético no núcleo da célula conduz a síntese protéica de acordo com as necessidades da célula. As células do corpo também podem usar parte do nitrogênio proveniente dos aminoácidos para formar os compostos de nitrogênio não-protéicos, como a creatina. Um exemplo é o das células musculares, que formam proteínas contráteis bem como as enzimas e o fosfato de creatina necessários à produção de energia. As células usam apenas a quantidade de aminoácidos necessária ao suprimento protéico. (GUYTON et al, 2002; WILLIAMS, 2002) Portanto, a síntese protéica ocorre por meio dos aminoácidos no sangue e nos fluidos corporais, que formam as proteínas, por meio das ligações peptídicas, e tem como destino a síntese dos tecidos corporais hormônios, enzimas e anticorpos. (COOMES, 1998; GUYTON et al, 2002; WILLIAMS et al, 2002)

As proteínas podem ser formadas também, a partir de gorduras e carboidratos, mas com algumas limitações importantes. O nitrogênio da proteína não está presente nesses dois outros macronutrientes. No entanto, se o organismo tiver excesso de aminoácidos, o fígado será capaz de usar os grupos amina, que contém nitrogênio, desse excesso e combiná-los com os aminoácidos oriundos do metabolismo de carboidrato e de gordura. O resultado será, portanto, a síntese de aminoácidos não-essenciais a partir desses nutrientes. (GUYTON et al, 2002; WILLIAMS, 2002)

A proteína dos alimentos consiste de aminoácidos de cadeias longas e complexas. No processo digestivo, as proteases do estômago e do intestino delgado transformam a proteína complexa em polipeptídeos e, depois, em aminoácidos individuais. Os aminoácidos são absorvidos pelas paredes do intestino delgado, passam para o sangue e para o fígado por meio da veia porta. Há intercâmbio constante entre os aminoácidos do sangue, do fígado e dos tecidos corporais. O fígado é um 
centro importantíssimo para o metabolismo dos aminoácidos; constantemente, sintetiza uma mistura equilibrada de aminoácidos para atender as diversas exigências do organismo. Esses aminoácidos são secretados no sangue e transportados como aminoácidos livres ou proteínas plasmáticas, como albumina. (GUYTON et al, 2002; WILLIAMS, 2002)

Como o corpo não dispõe de mecanismo para estocar o excesso de nitrogênio, não pode estocar o excesso de aminoácidos isolados ${ }^{7}$. O nitrogênio está presente no grupo amina (NH2), que é removido do aminoácido pelo processo de desaminação, deixando um substrato, o á-cetoácido, precursor de outros aminoácidos. Por exemplo, o ácido pirúvico, formado na glicólise, é o cetoácido precursor da alanina. Isso ocorre pelo processo de transaminação, em que um radical amino é transferido para o á-cetoácido, enquanto o oxigênio ceto é transferido para o doador do radical amino. Essa transaminação é promovida por enzimas, entre as quais as aminotransferases, derivadas da piridoxina, uma das vitaminas B (B6). Na ausência desta, os aminoácidos são sintetizados apenas em quantidade insuficiente, de modo que a formação de proteínas não pode prosseguir normalmente. (MAUGHAN, 2000; GUYTON et al, 2002; WILLIAMS, 2002) Como o excesso de nitrogênio deve ser eliminado do organismo, o fígado forma a amônia (NH3), a partir do nitrogênio em excesso, que é convertida em uréia, que é eliminada pela urina.

\section{Metabolismo no exercício físico}

O exercício produz alterações significativas em todo o metabolismo corporal. (FOSS, 2000) As forças determinantes das alterações são fatores que definem o exercício: intensidade, duração e resistência. (HAWLEY, 2002)

Durante o exercício, as respostas metabólicas parecem designadas a assegurar a energia necessária para sustentar as contrações miofibrilares, enquanto respostas prolongadas resultam em modificações de proteínas estruturais e em composição corpórea para maximizar o desempenho. Os papéis e a degradação de aminoácidos no corpo são diversos, variam de papel primário na síntese protéica até, finalmente, sofrer a degradação de catabolismo a energia e produtos nitrogenados da quebra. (WOLINSKY et al, 2002)

O exercício aeróbico exaustivo produz condição catabólica transitória. (LOON et al, 2000) Há quebra líquida de proteínas pela inibição da síntese protéica, com quebra remanescente constante de proteínas ou possivelmente aumentada. A magnitude dessa condição catabólica é dependente de intensidade e duração do exer-

cício e resulta na liberação de aminoácidos dos tecidos viscerais e do músculo 
esquelético. Essa condição é transitória, com a recuperação ocorrendo de 4 a 8 horas após o exercício e dirigida por aumentos na síntese protéica. (LEMON, 1996; WOLINSKY et al, 2002)

A quebra de proteínas durante o exercício aumenta o fluxo de aminoácidos e oxidação dos BCAA (leucina, isoleucina, valina), aminoácidos indispensáveis de cadeia ramificada. (LEMON, 1996) As avaliações das condições para a degradação de aminoácidos sugerem que a oxidação da leucina seja alta durante os exercícios exaustivos por indivíduos não-treinados. O treino atua reduzindo a oxidação de leucina em carga específica de trabalho. São necessárias investigações futuras em relação aos efeitos do exercício sobre outros aminoácidos indispensáveis e a definição das condições da dieta e do exercício que aumentam a recuperação no pós-exercício. (LEMON, 1996; LOON et al, 2000; WOLINSKY et $a l, 2002)$ As proteínas constituem, portanto, importantes substratos energéticos, em particular, nos exercícios de longa duração praticados por indivíduos treinados e no período de recuperação. (LEMON, 1996; HIRSCHBRUCH et al, 2002)

\section{Proteínas e exercício físico}

O exercício físico implica alterações metabólicas importantes no organismo, principalmente, no que se refere ao turnover protéico do músculo esquelético. (FOSS, 2000) O treinamento promove adaptações musculares, tornando-o mais apto a repetir contrações sucessivas, decorrentes do aumento da concentração de proteínas. O efeito sobre a concentração de proteínas no músculo esquelético varia de acordo com o tipo, a intensidade e a duração da atividade motora. (HIRSCHBRUCH et al, 2002)

Uma vez que os aminoácidos são necessários para sintetizar novas proteínas e que alguns são encontrados apenas na alimentação, um consumo adequado de proteínas é importante aos indivíduos que desejam aumentar massa e força musculares. (ADA, 2000) Todavia, esse aumento não ocorre somente com maior consumo protéico. Sem o estímulo do treinamento de força apropriado, os aminoácidos ingeridos em excesso serão convertidos e armazenados na forma de gorduras ou carboidratos, e o excesso de nitrogênio, excretado pela urina. (INSTITUTE SPORTS SCIENCE EXCHANGE, 1996; MARZZOCO, 1990; MARANGON, 2003)

Os fatores mais importantes para otimizar o crescimento muscular, quando a pessoa pratica exercícios, são: assegurar que a resistência seja adequada, que a ingestão energética na dieta seja suficiente, que, pelo menos, uma quantidade pequena de proteínas e/ ou de carboidratos seja consumida imediatamente após cada ses- 
são de treinamento e que o indivíduo descanse bastante entre as sessões de treinamento. (GIBALA et al, 2001)

\section{Balanço nitrogenado}

Existe balanço nitrogenado equilibrado quando a ingestão de nitrogênio (proteína) iguala-se à excreção de nitrogênio. (MANUAL OF CLINICAL DIETETICS, 1992) Se o balanço nitrogenado é positivo, ou seja, a ingestão é maior que a excreção de nitrogênio, a proteína será retida à medida que forem sintetizados novos tecidos. (FOSS, 2000) Isso ocorre, por exemplo, durante o treinamento com exercícios de resistência, quando ocorre a síntese protéica nas células musculares. O contrário é o balanço nitrogenado negativo, em que a excreção de nitrogênio supera a ingestão, indicando que a proteína é utilizada para a produção de energia assim como a possível espoliação dos aminoácidos existentes no organismo, principalmente aqueles presentes no músculo esquelético. É o que poderia ocorrer se o corpo catabolizasse proteína em virtude da ausência de outros nutrientes energéticos. (MCARDLE et al, 1998; LEVIN, 1999)

\section{Equilíbrio protéico}

A RDA (Recommended Daily Allowance) (1989) recomenda o consumo de 0,8 grama de proteína por quilo de peso corporal; o seu consumo pela maioria dos atletas é bem acima do recomendado, suprindo, adequadamente, as necessidades do organismo, nos exercícios físicos e nos treinos. Tal fato é comprovado por crescente número de evidências que indicam que as necessidades protéicas, tanto para força quanto para resistência física de indivíduos, variam de 1,0 a 2,0 gramas por quilo de peso corpóreo. (LEMON, 1996; INSTITUTE SPORTS SCIENCE EXCHANGE, 1996)

Se a ingestão energética não for igual ao dispêndio energético durante treinamento intensivo, a ingestão aumentada de proteína, duas vezes a RDA, pode ser suficiente para manter o balanço nitrogenado. A esse respeito, fazer dieta poderá afetar negativamente os esquemas de treinamento que pretendem aumentar a massa muscular ou manter alto nível de potência ou força. (MCARDLE et al, 1998)

Lemon \& Proctor (1991) descreveram que a atividade física moderada determina maior necessidade de proteína que a atividade intensa. Assim, tornou-se evidente a necessidade de investigar as relações existentes entre as proteínas e o exercício, principalmente quais seriam os mecanismos que determinam maior necessidade desse nutriente com relação à intensidade do exercício. 
Há grande importância da dieta rica em carboidratos como meio de conservar a proteína muscular para os praticantes de atividade física, visto que os carboidratos funcionam como poupadores de proteína, já que a utilização de proteínas para a obtenção de energia durante o exercício é maior quando os indivíduos se exercitam no estado com depleção de oxigênio. (WELKER, 2002) Este fato sugere que a demanda imposta às "reservas" de proteínas no exercício está vinculada à disponibilidade de carboidratos. (MCARDLE et al, 1998)

\section{Nos exercícios de força}

A atividade física tem profundos efeitos no metabolismo protéico. (FOSS, 2000) Por exemplo, se um músculo trabalha intermitentemente contra uma sobrecarga significante, como exercícios de resistência ou de força, o resultado, após um período de treinamento, é um efeito anabólico. (McARDLE et al, 1998) Isto ocorre porque o estímulo da síntese da proteína miofribilar excede-se no aumento da degradação protéica. Apesar da natureza intensa dessa atividade física, os aminoácidos aparecem para contribuir insignificantemente na oferta de combustível, pelo menos nos exercícios de resistência. (LEMON, 1996) Se o músculo trabalha ritmicamente contra excesso de carga moderado, o resultado é aumento na mitocôndria (enzimática) e, não, a síntese de proteína miofibrilar. Além disso, durante esse tipo de exercício, a quantidade total de aminoácidos oxidados pode ser significante. (LEMON, 1996)

Embora o catabolismo da proteína possa ocorrer durante o exercício, ou após o treinamento, o período de recuperação é marcado por aumento da síntese de proteína. (ADAS, 2000) Muitos estudos comprovam que, após o exercício ou endurance, o equilíbrio de proteína mantém-se ou torna-se positivo. (WILLIAMS, 2002)

De acordo com pesquisas, o consumo de proteínas revelado pela maioria dos atletas de força é maior que as necessidades sugeridas pela maior parte dos estudos que utilizam a técnica do balanço de nitrogênio. Isto pode significar que, embora seja possível manter um balanço positivo dos níveis de nitrogênio durante um programa de treinamento de força, com a ingestão de proteína igual ou um pouco acima da RDA, o maior consumo é necessário para gerar aumento ideal de volume e força muscular. (LEMON, 1996) 


\section{Suplementos protéicos}

O aspecto mais em moda na nutrição esportiva é o consumo de suplementos nutricionais, principalmente os compostos de proteínas especiais, aminoácidos e subprodutos do metabolismo da proteína, em decorrência da potencial capacidade de melhoraria do desempenho físico. (ITALO, 1995) Os atletas acreditam que esses suplementos lhes darão maior vantagem nas competições quando podem tornar-se prejudiciais tanto para a saúde quanto para o desempenho. (INSTITUTE SPORTS SCIENCE EXCHANGE, 1996; ITALO, 1998)

O problema está na freqüência em que determinadas substâncias são comercializadas sem base em qualquer pesquisa científica que determine seus benefícios potenciais ou possíveis efeitos colaterais nocivos. Alguns suplementos entram e saem da moda, antes que se façam estudos para estabelecer seus efeitos. (INSTITUTE SPORTS SCIENCE EXCHANGE, 1996)

Para alguns especialistas, as proteínas vindas da alimentação normal são tão eficazes quanto os suplementos de aminoácidos no aumento do crescimento muscular. (LEMON, 1996) Aparentemente, o fator mais importante no crescimento muscular é o tempo da ingestão de proteína após o exercício, não a mistura específica dos aminoácidos ou o tipo de proteína ingerida. (ADA, 2000; LOON et al, 2000) Os suplementos especiais podem ser úteis a determinadas populações, por exemplo, pacientes com queimaduras, pessoas da terceira idade e indivíduos que não podem sair da cama, para os quais a perda muscular representa problema. (GIBALA et al, 2001)

É importante lembrar o fato de que esses suplementos devem ser usados como auxiliares de plano nutricional balanceado, e não como substituto. No entanto, os efeitos da suplementação de proteína no desempenho físico, além dos efeitos do treinamento, ainda não são conhecidos. O consumo de misturas de aminoácidos específicos ou dietas com alto conteúdo de proteína podem causar desequilíbrio nutricional, pois a sobrecarga de um aminoácido pode inibir a absorção de outros. (WILLIAMS, 2002)

O interesse de atletas de força em otimizar a retenção de nitrogênio e ganhos protéicos com a utilização desses produtos e o intensivo marketing são fatores que estimulam o uso destas substâncias. (APPLEGATE et al, 1997) Portanto, torna-se imprescindível a orientação de profissionais especializados em nutrição esportiva e educação física na prescrição de substâncias ergogênicas. O uso indiscriminado de proteínas pode contribuir para o aparecimento de patologias associadas, além de não ser benéfico para o organismo. Quando o atleta, ou mesmo o praticante de exercício, tem acompanhamento nutricional e físico adequados, as conseqüências envolvem a performance e a qualidade de vida. 


\section{Conclusões}

É sugerida a ingestão diária de 1,2 a 1,4 grama de proteína por quilo de peso corporal (150-167\% da RDA) para os exercícios de endurance e 1,7 a 1,8 grama de proteína por quilo de peso corpóreo (212-225\% da RDA) para os exercícios de força. (LEMON, 1996) No entanto, não se sabem, ao certo, as quantidades essenciais para o anabolismo.

A suplementação de aminoácidos individuais pode ser benéfica para os indivíduos fisicamente ativos, mas considerável risco também está presente. A ingestão de grandes quantidades desses aminoácidos não é recomendada. (LEMON, 1996)

Não se sabe se o alto consumo protéico favorece o desenvolvimento muscular ou causa riscos à saúde. Para que essas observações sejam confirmadas, mais estudos são necessários. Só então será possível determinar a quantidade de proteína necessária para maximizar o aumento da força e do volume muscular já estimulado pelo treinamento, sem que haja prejuízo dos praticantes de exercício físico.

\section{Referências}

APPLEGATE, E A.; GRIVETTI, L. E.; American Society for Nutritional Sciences, 00223166/97, 1997.

ARAÚJO, A. C. M; SOARES, Y. N. G..Rer. Nutr., Campinas, 12(1): 81-89, jan./abr., 1999.

COOMES, M. W. in DEVLIN, T. M. Manual de Bioquímica com Correlações Clínicas. São Paulo: Edgard Blucher, , 1998.

DUTRA, O; MARECHINI, J. S. Ciências Nutricionais. São Paulo: Sarvier, 1998.

Food and Nutrition Board, National Research Council, National Academy of Sciences. In: Recommended Dietary Allowances. 10. ed. Washington: Natonal Academy Press, 1989.

FOSS, M. L.; KETEYIAN, S. J. Fox: Bases Fisiológicas do Exercício e do Esporte. 6. ed. Rio de Janeiro: Guanabara Koogan S.A, 2000.

GIBALA, M. S.; TIPTON, K.; HARGREAVES, M.. Aminoácidos, proteínas e desempenho físico. São Paulo: Gatorade Sports Science, abril/maio/junho, 2001.

GUYTON, Arthur C.; HALL, Jonh E.. Tratado de Fisiologia Médica. 10 ed. Rio de Janeiro: Guanabara Koogan, 2002.

HAWLEY, J. A "Symposium: limits to fat oxidation by skeletal muscle during exercise". In: Med. Sci. Sports. Exerc., 34: 1475-1476. 2002. 
HIRSCHBRUCH, Márcia Daskal; CARVALHO, Juliana Ribeiro. Nutrição Esportiva: uma visão prática. São Paulo: Manole, 2002.

Institute Sports Science Exchange. A importância da Proteína. In: Gatorade Sports Science: São Paulo.

ITALO. International School of Sports Nutrition ans Human Performance. Advanced Sports Nutrition. Symposium series 002, Vol I, 1995.

LEMON, P.W.R.. Nutrition Reviews. Vol 54, n4, 1996. . Institute Sports Science Exchange. Influência da Proteína Alimentar e do Total de Energia Ingerida no Aumento da Força Muscular. In: Gatorade Sports Science: São Paulo.

LEVIN, R. J. IN: SHILS, M. E; OLSON, J. A., SHIKE, M. Modern Nutrition in Health and Disease. 9. ed, USA, 1999.

LOON, L. J. C. et al. "Ingestion os Protein Hydrolysate and Amino Acid-Carbohydrate Mixtures Increases Postexercise Plasma Insulin Response in Men”. In: J. Nutr., 130: 2508-2513, 2000.

MARANGON, A F. C.; WELKER, A F. "Otimizando a perda de gordura corporal durante os exercícios”. In: Universitas - Ciências da Saúde. Vol. 1, n. 2, 2003.

MARZZOCO, A., TORRES, B. B. Bioquímica Básica. Rio de Janeiro: Guanabara Koogan S.A., 1990.

MAUGHAN, R.; GLEESON, M. \& GREENHALF, P. L. Bioquímica do exercício de do treinamento. São Paulo: Manole, 2000.

MCARDLE, William D.; KATCH, Frank I.; KATCH, Victor L. Fisiologia do Exercício. 4 ed. Rio de Janeiro: Guanabara Koogan, 1998.

PASTOR, V. J.; RUIZ, M.; ACOSTA, A.M. \& AVILA, C. "Metabolic and hormonal changes during aerobic exercise indistance runners". In: J. Physiol. Biochem, , 55: 7-16, 1999.

Position of the American Dietetic Association, Dietitians of Canada, and the American College os Sports Medicine: Nutrition and athletic performance. In: J Am Diet Assoc; 100:1543 - 1556, 2000.

ROCHA, P. L.; PEREIRA, V. L.. Rev. Nutr., Campinas, 11(1): 76-82, jan./jun., 1998.

SHILS, Maurice E.; OLSON, James A.; SHIKE, Moshe. Tratado de Nutrição Moderna na Saúde e na Doença. 9 ed. São Paulo: Manole, 1 vol, 2003.

WELKER, A F.; SOUZA, P. F. Efeito da iongestão de carboidrato sobre o metabolismo lipídico durante o repouso após exercício. In: Arq. Brás. Endocrinol. Metab, 46: supl. 1, 505-505, 2002.

WILLIAMS, Melvin H. Nutrição para saúde, condicionamento físico e desempenho esportivo. 5 ed. São Paulo: Manole, 2002.

WOLINSKY, Ira; JUNIOR, James F. Hickson. Nutrição no Exercício e no Esporte. 2 ed. São Paulo: Roca, 2002.

http://www.efmuzambinho.org.br/refelnet/revusp/edicoes/1996/uspv10n1/6junio.htm, acessado em 20/02/2004. 